\title{
Sistem Pakar Berbasis Web Dengan Metode Forward Chaining Dalam Mendiagnosis Dini Penyakit Tuberkulosis di JawaTimur
}

\author{
Windah Supartini ${ }^{\star 1}$, Hindarto ${ }^{2}$ \\ 1, 2 Universitas Muhammadiyah Sidoarjo \\ windaumsida@gmail.com¹, hindarto@umsida.ac.id²
}

\begin{abstract}
Abstrak
Tuberkulosis adalah suatu penyakit menular berbahaya yang disebabkan oleh kelompok Mycobacterium, yaitu Microbacterium Tuberkulosis. Setiap pasien Tuberkulosis dapat menularkan penyakitnya pada orang lain yang berada di sekelilingnya dan atau yang berhubungan erat dengannya. Karena masih banyak orang yang tidak mengetahui gejala-gejala penyakit suatu sistem pakar mendiagnosis secara dini penyakit tuberkulosis menggunakan metode forward chaining berbasis web, dapat dikenali dengan melihat gejala-gejala dengan mendeteksi penyakit sejak dini, dilakukan pencegahan terhadap penyakit tuberkulosis. Diagnosis sistem pakar, memiliki nilai keakuratan 93,333 \% dan nilai eror 6,667 \% untuk uji coba pada 15 pasien. Sehingga dapat disimpulkan bahwa sistem pakar cukup layak untuk digunakan oleh pasien dalam mendiagnosis dini pada penyakit tuberkulosis.
\end{abstract}

Kata Kunci: Tuberkulosis, Forward Chaining, Sistem Pakar, Web

Abstract
Tuberculosis is a contagious disease caused by Mycobacterium family; Mycobacterium Tuberkulosis. Every patient of tuberculosis could possibly transmit this disease to people around him, or to people that closely related to him. Because there are still many people do not really know about the symptoms, an expert system is developed to diagnose tuberculosis by using web-based forward chaining method; by recognizing the disease earlier, the prevention could be conducted appropriately. Diagnoses expert system has $93.333 \%$ accuracy and $6.667 \%$ errors as experimented to 15 patients. Therefore, it could be concluded that expert system is adequate to be used by patients to diagnose tuberculosis disease.

Keywords: Tuberculosis, Forward Chaining, Expert System, Web

\section{Pendahuluan}

Tuberkulosis adalah suatu penyakit menular berbahaya yang disebabkan oleh dari kelompok Mycobacterium, yaitu Mycobacterium Tuberkulosis. Setiap pasien Tuberkulosis dapat menularkan penyakitnya pada orang lain yang berada di sekelilingnya dan berhubungan erat dengannya [1].

Jumlah pasien TB di Indonesia merupakan jumlah ketiga di dunia setelah India dan Cina. Dari hasil persentase antara lain India 21.1\%, China $14.3 \%$, Indonesia 5.8\%, Nigeria 4.9\%, Ethiopia 3.3\%, Pakistan $3.2 \%$, dan lainnya $15.9 \%$. Setiap tahun diperkirakan terjadi 583.000 pasien baru TB setiap tahun, diperkirakan 140.000 orang meninggal karena TB. Setiap menit muncul satu orang pasien TB Paru Baru, setiap 2 menit muncul satu orang penderita TB Paru yang menular, setiap 1 menit satu orang meninggal akibat TB. Setiap hari sekitar 400 orang meninggal karena TB yang sebanding dengan jumlah korban penumpang pesawat jenis boeing seri 747 yang jatuh setiap hari. TB merupakan penyebab kematian nomor satu dari golongan penyakit infeksi, dan nomor tiga penyebab kematian pada semua kelompok usia setelah penyakit jantung dan penyakit saluran pernafasan. Saat ini, program penanggulangan TB dengan Strategi DOTS (Directly Observed Treament Short-course) atau disebut dengan pengawasan langsung jangka pendek belum dapat menjangkau seluruh Puskesmas, Rumah Sakit Pemerintah atau Swasta, serta unit pelayanan kesehatan lainnya [1].

Jumlah penderita TB dapat ditekan dengan adanya tindakan pendeteksian dini gejala penyakit TB. Oleh karena hal tersebut, dibutuhkan suatu aplikasi system pakar agar mudah digunakan oleh orang awam mendiagnosis penyakit Tuberkulosis. 


\section{Metode Penelitian}

Dalam penelitian ini, metode yang dilakukan, adalah memeriksa berkas pasien Tuberkulosis dan melakukan wawancara di sub recipient TB Care Aisyiyah Jawa Timur yang beralamatkan di Jl. Kertomenanggal IV No.1 Gayungan, Kota Surabaya, Jawa Timur, 60234 dengan dokter yang direkomendasikan untuk penelitian dari Rumah Sakit/Puskesmas Program Penanggulangan TB Care Aisyiyah, yaitu dr. Daniek Suryaningdiah sebagai dokter yang menangani program penyakit Tuberkulosis.

\subsection{Bahan Penelitian}

Bahan yang digunakan untuk penelitian ini adalah data-data dari dalam buku Pedoman Nasional "Pengendalian Tuberkulosis" oleh (Kementerian Kesehatan Republik Indonesia Direktorat Jendral Pengendalian penyakit dan Penyehatan Lingkungan, 2014), serta data dari sub recipient TB Aisyiyah Jatim dan setiap sub recipient TB Aisyiyah Surabaya, "Artificial Intelligance" oleh Suyanto, ST., MSC. Serta buku-buku dan sumber lain yang menunjang pembuatan Perancangan Sistem Pakar Berbasis Web dengan metode Forward Chaining dalam upaya mendiagnosis dini penyakit Tuberkulosis di Jawa Timur.

\subsection{Teknik Pengumpulan Data}

Adapun teknik pengumpulan data yang digunakan untuk penelitian sistem pakar diagnosis penyakit Tuberkulosis berbasis web dengan metode Forward Chaining adalah sebagai berikut:

\subsubsection{Studi pustaka}

Dalam penelitian ini, dilakukan pencarian dan pembelajaran dari berbagai macam sumber pustaka. Di antaranya data program penanggulangan TB di Jawa Timur oleh SR TB Aisyiyah Jawa Timur informasi dari dokter spesialis penanganan penyakit Tuberkulosis, bukubuku, jurnal, dan website yang berkaitan dengan perancangan sistem pakar berbasis web dengan metode Forward Chaining dalam upaya mendiagnosis dini penyakit Tuberkulosis di Jawa Timur.

\subsubsection{Observasi}

Observasi adalah mengadakan penelitian dan analisis secara langsung terhadap data yang akan diteliti, yaitu mengamati ciri-ciri dan keluhan orang yang diduga TB (Suspek) dengan cara tes uji coba penggunaan sistem pakar sampai dapat diketahui hasilnya negatif/positif dan jika positif maka dapat diketahui Klasifikasinya.

\subsubsection{Wawancara}

Dalam pengembangan sistem pakar, dilakukan tanya jawab secara langsung kepada dokter spesialis penyakit Tuberkulosis untuk mendapatkan informasi yang dibutuhkan dalam proses perancangan sistem pakar berbasis web dengan metode Forward Chaining dalam upaya mendiagnosis dini penyakit Tuberkulosis di Jawa Timur.

\subsection{Sistem Pakar}

Sistem pakar merupakan cabang dari Al (Artificial Inteligent) yang membuat ekstensi untuk spesialisasi pengetahuan guna memecahkan suatu permasalahan pada Human Expert. Human Expert merupakan seseorang ahli dalam suatu bidang ilmu pengetahuan tertentu, berarti expert memiliki suatu permasalahan yang tidak dapat dipecahkan oleh orang lain secara efisien.

\subsubsection{Forward Chaining}

Forward Chaining merupakan fakta untuk mendapatkan kesimpulan (conclusion) dari fakta tersebut. [2] Penalaran ini berdasarkan fakta yang ada (data driven), metode ini adalah kebalikan metode Backward Chaining, dimana metode ini dijalankan dengan mengumpulkan fakta-fakta yang ada untuk menarik kesimpulan. Dengan kata lain, prosesnya dimulai dari facts (fakta-fakta yang ada) melalui proses interface fact (penalaran fakta-fakta) menuju suatu goal (suatu tujuan). Metode ini juga disebut menggunakan aturan IF-THEN dimana premise (IF) menuju conclusion (THEN) atau dapat juga dituliskan sebagai berikut:

THEN (konklusi) 
Ada dua pendapat mengenai pelaksanaan metode ini. Pertama dengan cara membawa seluruh data yang didapat ke sistem pakar. Kedua dengan membawa bagian-bagian penting saja dari data yang didapat ke sistem pakar. Cara pertama lebih baik digunakan jika sistem pakar terhubung dengan proses otomatis dan penerima seluruh data dari database. Cara kedua menghemat waktu serta biaya dengan mengurangi data dan mengambil data yang dianggap perlu. Sebagai contoh, seperti kasus pada kedua metode di atas, maka berdasarkan metode ini langah-langkah yang diambil:

\author{
R1: IF $A$ and $C$, THEN B \\ R2 : IF D and C, THEN F \\ R3 : IF B and E, THEN F \\ R4 : IF B, THEN C \\ R5 : IF F, THEN G
}

Kedua jenis strategi ini akan mengarah pada suatu kesimpulan. Namun, efisiensinya tergantung dari kondisi masalah yang dihadapi, jika suatu masalah memiliki premis jumlahnya lebih sedikit dibanding conclusion, maka strategi yang akan ditawarkan Backward Chaining [3].

\title{
2.4 Perangkat Perancangan Sistem \\ 2.4.1 Basis data (Database)
}

Basis data atau database adalah kumpulan data yang disimpan secara sistematik di dalam komputer. Basisdata juga dapat diolah atau dimanipulasi menggunakan perangkat lunak atau program aplikasi untuk menghasilkan suatu informasi. Pendefinisian basis data meliputi spesifikasi berupa tipe data, struktur data, dan juga batasan-batasan data yang akan disimpan [4].

\subsubsection{Tabel Relasi}

Tabel relasi merupakan hubungan yang terjadi pada suatu tabel dengan tabel lain, yang berfungsi untuk mengatur operasi suatu database. Hubungan yang dibentuk dapat mencangkup tiga macam hubungan, yaitu [5]:

1. One-To-One (1-1)

2. One- to-Many $(1-\mathrm{N})$

3. Many-To-Many (N-M)

\subsubsection{Flowchart}

Flowchart atau diagram alir merupakan sebuah diagram dengan simbol-simbol grafis yang menyatakan aliran algoritma atau proses menampilkan langkah-langkah yang disimbolkan dalam bentuk kotak, beserta urutannya dengan menghubungkan masing-masing langkah tersebut menggunakan tanda panah. Diagram ini dapat memberi solusi langkah demi langkah untuk penyelesaian masalah yang ada dalam proses atau algoritma tersebut [3].

\subsubsection{Data Flow Diagram}

Data Flow Diagram (DFD) adalah diagram yang menggunakan notasi-notasi untuk menggambarkan arus dari data sistem, yang mana penggunaannya sangat membantu memahami sistem secara logika, terstruktur, dan jelas. DFD merupakan alat bantu dalam menggambarkan atau menjelaskan proses kerja suatu sistem informasi maupun sistem aplikasi [4].

Pada DFD terdapat 3 level, yaitu [6]:

1. Diagram Konteks, merupakan level tertinggi dari DFD, yang mana menggambarkan tentang seluruh input dan output dari suatu sistem.

2. Diagram Nol, Merupakan pemecahan dari diagram konteks. Dalam diagram nol ini memuat penyimpanan data dan proses dari suatu sistem.

3. Diagram Rinci, merupakan uraian proses dari diagram nol atau diagram di level atasnya dalam suatu sistem.

\subsection{Mesin Inferensi}

Dalam sebuah sistem pakar dibutuhkan sebuah mesin sistem inferensi yang akan menjadi pengendali dari sebuah sistem pakar. Mesin inferensi merupakan fungsi berpikir dan 
pola penalaran sistem yang digunakan oleh sistem pakar. Mekanisme ini akan menganalisis suatu masalah dan selanjutnya akan mencari jawaban serta kesimpulan yang terbaik. Teknik dalam mesin inferensi sistem pakar pada Gambar 1 adalah metode Forward Chaining.

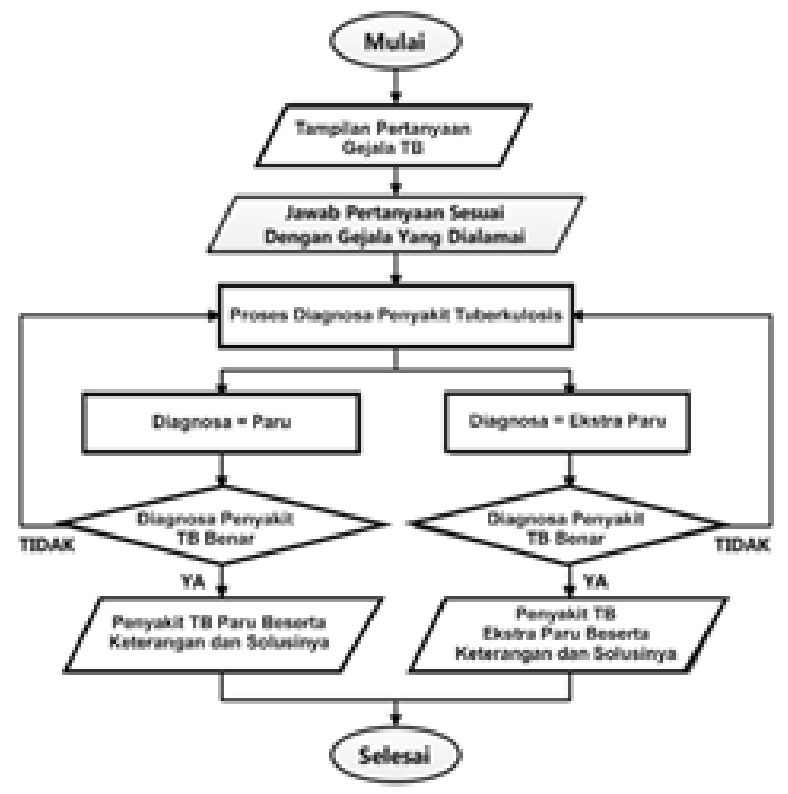

Gambar 1. Mesin Inferensi Sistem Pakar Mendiagnosis Penyakit Tuberkulosis

\subsubsection{Analisis}

Basis Pengetahuan Gejala Penyakit Tuberkulosis, terpapar pada Tabel 1.

Tabel 1. Tabel Relasi Gejala pada Penyakit Tuberkulosis

\begin{tabular}{|c|c|c|c|}
\hline & \multicolumn{3}{|c|}{ Penyakit } \\
\hline Kode & P001 & P002 & P003 \\
\hline G001 & $\mathrm{X}$ & $X$ & \\
\hline G002 & $X$ & $X$ & \\
\hline G003 & $X$ & & \\
\hline G004 & $\bar{X}$ & & \\
\hline G005 & $X$ & & \\
\hline G006 & $X$ & & \\
\hline G007 & $X$ & & \\
\hline G008 & $X$ & & \\
\hline G009 & $X$ & & \\
\hline G010 & $\bar{x}$ & & \\
\hline G011 & & 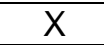 & \\
\hline G012 & & $X$ & \\
\hline G013 & & $x$ & \\
\hline G014 & & $X$ & \\
\hline G015 & & & $X$ \\
\hline G016 & & & $X$ \\
\hline G017 & & & $x$ \\
\hline G018 & & & $X$ \\
\hline G019 & & & $X$ \\
\hline G020 & & & $X$ \\
\hline G021 & & & $X$ \\
\hline G022 & & & $X$ \\
\hline G023 & & & $x$ \\
\hline G024 & & & $x$ \\
\hline G025 & & & $X$ \\
\hline G026 & & & $X$ \\
\hline
\end{tabular}


3. Hasil Penelitian dan Pembahasan

\subsection{Form antarmuka pemakai}

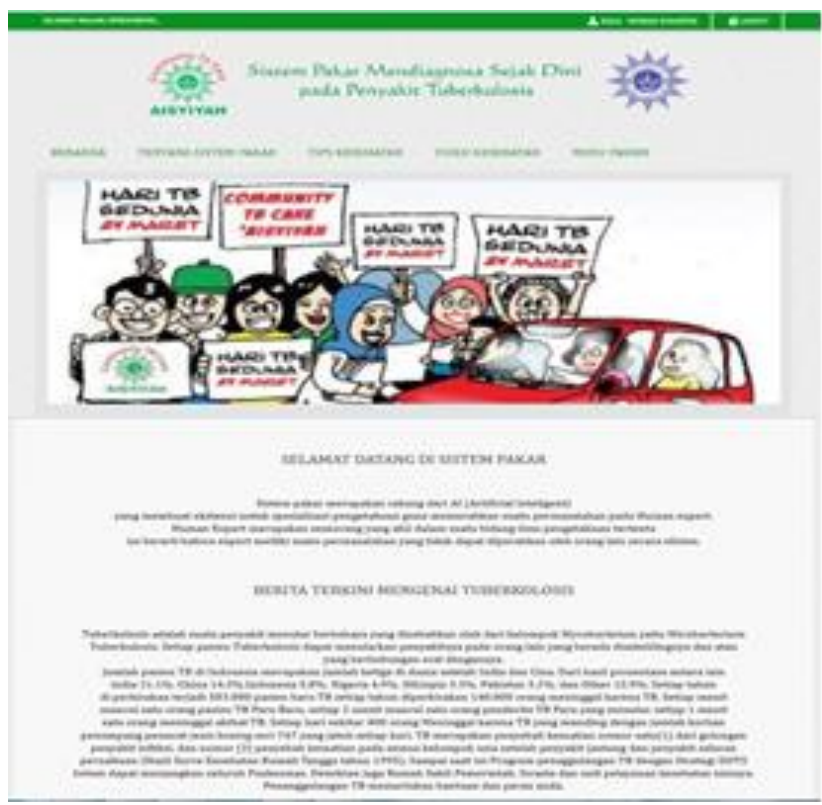

Gambar 2. Tampilan Utama Sistem Pakar

Tampilan Gambar 2 merupakan tampilan utama sistem pakar yang akan dijumpai oleh user. Tampilan ini berisi tentang sambutan dan berita terkini mengenai penyakit Tuberkulosis yang ditujukan untuk user sistem pakar.

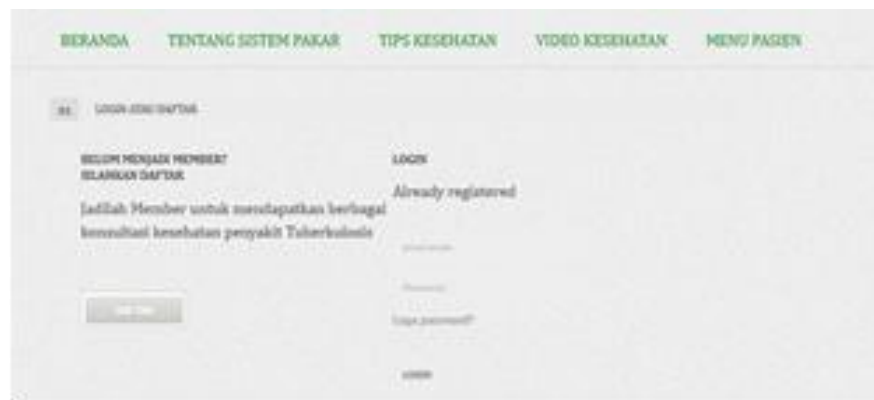

Gambar 3. Tampilan Menu User

Tombol registrasi Gambar 3 digunakan untuk pendaftaran pasien. Serta terdapat form login user digunakan untuk login pada tampilan utama menu pasien.

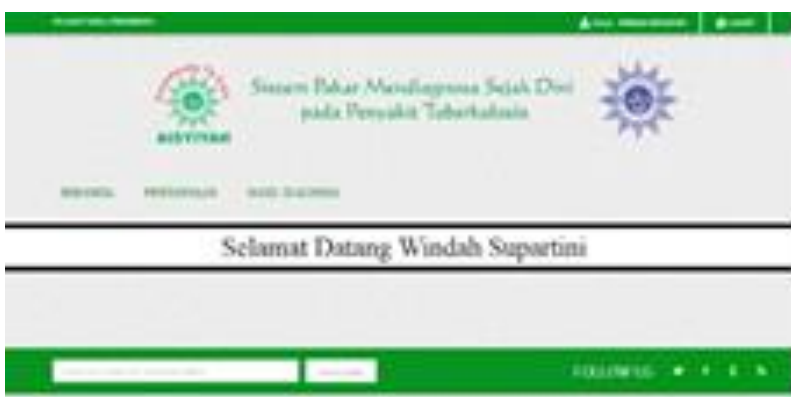

Gambar 4. Tampilan Utama Menu Pasien

Gambar 4 adalah tampilan menu pasien yang sudah login, muncul menu pertanyaan untuk mengetahui diagnosis pasien dan selanjutnya menu hasil riwayat diagnosis. 


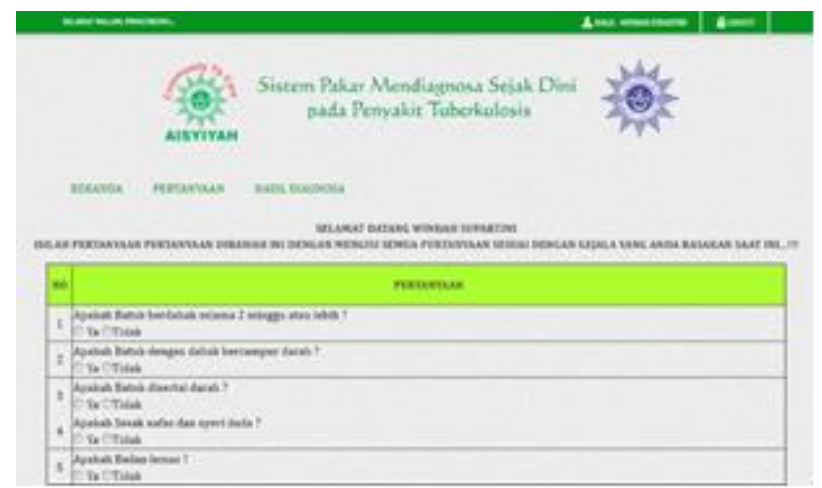

Gambar 5. Tampilan Form Diagnosis Penyakit Tuberkulosis

Pada Gambar 5, terdapat tampilan form diagnosis penyakit Tuberkulosis, terdapat beberapa pertanyaan seputar gejala Tuberkulosis secara umum dan spesifik harus diisi oleh pasien untuk mengetahui jenis penyakit Tuberkulosis yang diderita oleh pasien saat ini.

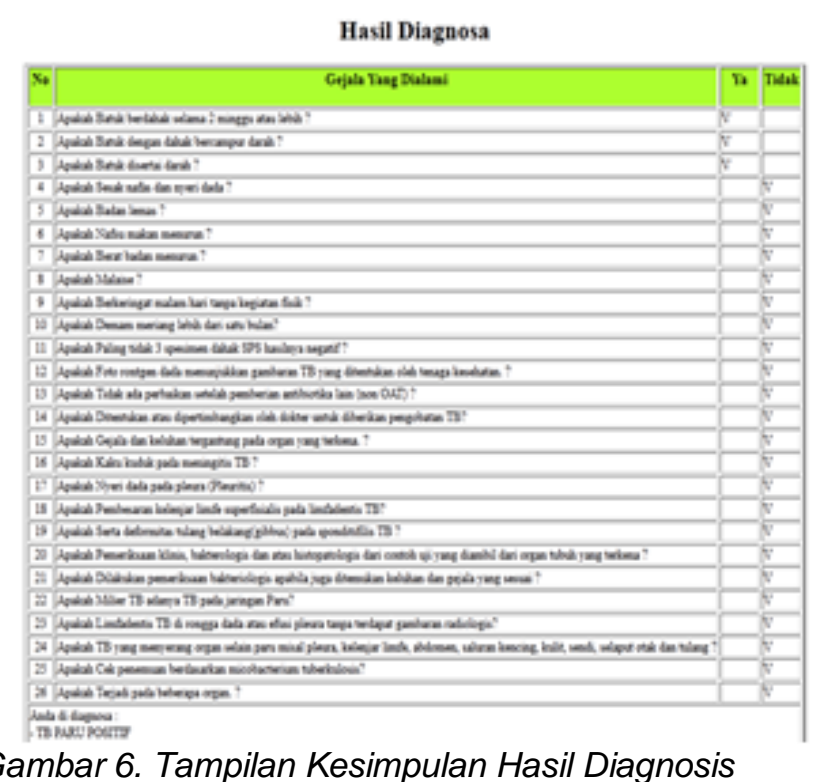

Gambar 6. Tampilan Kesimpulan Hasil Diagnosis

Pada tampilan Gambar 6, pasien dapat mengetahui gejala-gejala yang sudah dialami termasuk dapat diketahui jenis penyakit yang diderita oleh pasien saat ini.

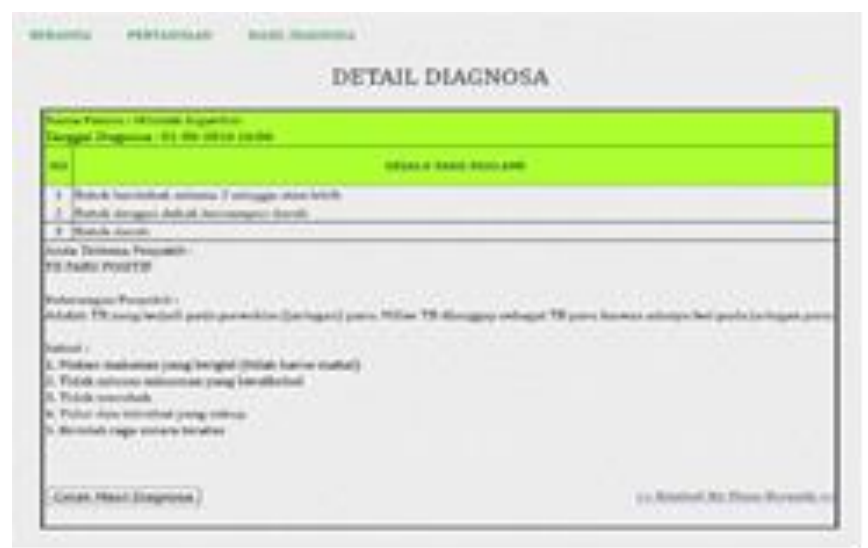

Gambar 7. Tampilan Hasil Diagnosis Penyakit Tuberkulosis

Pada tampilan Gambar 7 adalah hasil diagnosis penyakit Tuberkulosis, pasien dapat mengetahui jenis penyakit Tuberkulosis yang sedang diderita saat ini, serta mendapatkan 
keterangan dan solusi penyakit Tuberkulosis tersebut. Pasien juga dapat mencetak hasil diagnosis.

\subsection{Perbandingan Hasil Diagnosis Sistem Pakar dengan Diagnosis Dokter}

Tabel 2, 3, dan 4 adalah perbandingan hasil diagnosis penyakit Tuberkulosis menggunakan sistem Pakar dengan hasil diagnosis dokter yang sesungguhnya.

1. Pasien 1

Nama Pasien : Rukanah

Umur : :53 Tahun

Gejala: Batuk berdahak selama 2 minggu atau lebih, batuk dengan dahak bercampur darah, batuk disertai darah, sesak nafas dan nyeri dada, badan lemas, nafsu makan menurun, berat badan menurun.

Tabel 2. Perbandingan Hasil Diagnosis Pasien 1

\begin{tabular}{cc}
\hline Diagnosis Sistem Pakar & Diagnosis Dokter \\
\hline $\begin{array}{c}\text { Tuberkulosis Paru } \\
\text { (positif) }\end{array}$ & Tuberkulosis Paru dengan Hasil Positif \\
\hline
\end{tabular}

2. Pasien 2

Nama Pasien : Musinem

Umur : :40 Tahun

Gejala: Batuk berdahak selama 2 minggu atau lebih, batuk dengan dahak bercampur darah, batuk disertai darah, sesak nafas dan nyeri dada, badan lemas, nafsu makan menurun, berat badan menurun, malaise, berkeringat malam hari tanpa kegiatan fisik, demam meriang lebih dari 1 bulan.

Tabel 3. Perbandingan Hasil Diagnosis Pasien 2

\begin{tabular}{cc}
\hline $\begin{array}{c}\text { Diagnosis Sistem Pakar } \\
\text { (positif) }\end{array}$ & Diagnosis Dokter \\
\hline $\begin{array}{cc}\text { Tabel 4. Perbandingan Hasil Diagnosis Pasien 15 } \\
\text { Diagnosis Sistem Pakar }\end{array}$ & Diagnosis Dokter \\
\hline $\begin{array}{c}\text { Tuberkulosis Paru } \\
\text { (positif) }\end{array}$ & $\begin{array}{c}\text { Tuberkulosis Paru } \\
\text { dengan Hasil Positif }\end{array}$ \\
\hline
\end{tabular}

Berdasarkan 15 perbandingan hasil diagnosis penyakit Tuberkulosis menggunakan sistem pakar dengan hasil diagnosis dokter di atas, terdapat 1 hasil diagnosis pasien menggunakan sistem pakar yang tidak sesuai dengan hasil diagnosis dokter, yaitu pada pasien 10. Maka dari itu, sistem pakar mendiagnosis secara dini pada penyakit Tuberkulosis mempunyai nilai error sesuai dengan Persamaan 1.

$$
\begin{gathered}
x=\frac{\mathrm{a}}{\mathrm{b}} \times 100 \% \\
=\frac{1}{15} \times 100 \%=6,667 \%
\end{gathered}
$$

Keterangan:

Angka 1 = Jumlah hasil nilai error (hasil diagnosis sistem pakar yang tidak sama dengan hasil diagnosis dokter).

Angka 15 = Semua jumlah hasil diagnosis.

Sedangkan nilai keakuratan dari sistem pakar mendiagnosis secara dini pada penyakit Tuberkulosis dihitung menggunakan Persamaan 2. 


$$
\begin{gathered}
x=\frac{\mathrm{a}}{\mathrm{b}} \times 100 \% \\
=\frac{14}{15} \times 100 \%=93,333 \%
\end{gathered}
$$

Keterangan:

Angka 14 = Jumlah hasil nilai yang akurat (hasil diagnosis sistem pakar yang sama dengan hasil diagnosis dokter).

Angka 15 = Semua jumlah hasil diagnosis.

\section{Kesimpulan}

Dari hasil perancangan, pembuatan, pengimplementasian, serta pengujian aplikasi sistem pakar mendiagnosis secara dini pada penyakit Tuberkulosis menggunakan metode Forward Chaining berbasis web, dapat diperoleh berbagai kesimpulan dan saran untuk perkembangan program aplikasi sistem pakar mendiagnosis secara dini pada penyakit Tuberkulosis ke arah yang lebih baik.

1. Sistem pakar mendiagnosis secara dini pada penyakit Tuberkulosis menggunakan metode Forward Chaining berbasis web ini cukup membantu untuk mendiagnosis penyakit Tuberkulosis berdasarkan gejala-gejala yang dikeluhkan oleh pasien.

2. Hasil diagnosis pakar dan user dari sistem pakar mendiagnosis secara dini pada penyakit Tuberkulosis menunjukkan bahwa hasil diagnosis yang dialami pasien menunjukkan sesuai dengan yang telah di diagnosis oleh dokter penyakit Tuberkulosis.

\section{Daftar Notasi}

\section{$x=\%$ error}

$\mathrm{a}=$ data pasien yang tidak sesuai dengan diagnosis

$\mathrm{b}=$ banyak data pasien yang diagnosis

\section{Referensi}

[1] Tim Pengembangan Modul. Pelatihan penanggulangan Tuberkulosis bagi Kader Komunitas. Penerbit Recipient TB Aisyiyah. Jakarta. 2009.

[2] Winarko, Edi. Perancangan Database Dengan Power Desaigner 6.32. Prestasi Pustakarya. Jakarta. 2006.

[3] Purwono, Edi. Sistem Analisis, ANDI. Yogyakarta. 2007.

[4] Azzolini, John. Introduction to System Engineering Practices, Yogyakarta: ANDI Offset. 2004.

[5] Ignizio, J.P. Introduction To Expert System: The Development and Implementation Of Rule-Based Expert System. McGraw-Hill International Editions. 1991.

[6] Girratano, Riley. Expert Sistem: Principles and Programming, PWS Publising Company, Boston. 1994. 